\title{
Isolation and Identification of Effective Hydrocarbon Degrading Bacteria from Diesel Polluted Soil
}

\author{
*Karthika ${ }^{1}$. R., Archaya ${ }^{2}$. S., Nandhini ${ }^{1}$. S., Gopinath ${ }^{1}$, L. R.Bhuvaneswari. R \\ ${ }^{I}$ Department of Biotechnology, Vivekanandha Educational Institutions, Tiruchengode, Namakkal, Tamilnadu. \\ ${ }^{2}$ Trust of Socio Economic and ecological Development (To SEED), Namakkal, Tamilnadu. \\ ${ }^{3}$ Department of Zoology, NKR Govt. Arts College for Women, Namakkal, Tamilnadu.
}

\begin{abstract}
Hydrocarbon pollution is due to accidental leakages, spills or by transportation. It might be carcinogenic to human, animal and plant health. Bioremediation is the best remedy to remove the pollutants from the environment. Diesel degrading microbes are widely distributed in our environment. The microbes may not be present in sufficient amount to achieve the degradation process in successfully. Inoculation of efficient hydrocarbon degrading bacterial strains in polluted area will enhance the capability of degradation. The present study was aimed to be isolating the effective bacterial strains from the polluted area to enhance the degradation. Totally fifteen isolates were identified and biochemically characterized. Among these two of them were effective degrader under 4\% diesel. Pseudomonas putida and Micrococcus luteus are the bacterial strains were able to degrade the contaminants in large amounts. In this study we report the bacterial strains capable of degrading the hydrocarbons efficiently. Degradation studies to be carried out with different isolates at different concentration of diesel to find out most potent hydrocarbon degrading strains, which can be used for any bioaugmentation studies during bioremediation
\end{abstract}

\section{Introduction}

Hydrocarbon pollution is one of the important concerns in the developing countries. It may cause extensive damage to the plant physiology and human health. Hydrocarbon mainly composed of carbon and hydrogen atoms with different proportions. Diesel, petroleum and crude oil are the best examples of hydrocarbons and they considered as the main sources of primary energy and fuel resources (Watanabe, 2000). Due to transportation, leakages, spills, major accidents in oceans the hydrocarbons accumulate our environment and cause contamination to ecosystems in worldwide (Massol-Deya et al., 2006).

There is a big challenge to remove the hydrocarbons from the environment in efficient manner (Thomassin, et al., 2002). Bioremediation is the important technique to remove the pollutants present in the environment (Vinas, et al., 2002). Bioremediation is less expensive and cheaper method to eliminate the contaminants. By using natural occurring microorganisms allows to conversion of highly toxic hydrocarbons into non toxic and it is represent as the primary mechanisms to remove the hydrocarbons from the environment (Okerentugba and Ezeronye, 2003). The microorganisms utilize the hydrocarbon as sole carbon source and energy.The present work aimed to isolate novel bacterial strains capable of degrading the diesel degradation in situ conditions. In this study we identified the bacterial strains capable of degrading the hydrocarbons.

\section{Materials and methods}

The soil samples were collected from diesel polluted areas near Namakkal, Tamilnadu, India. The samples were transferred into sterile polythene bags and took into the laboratory for further analysis. One gram of soil sample was taken and serially diluted up to 8 dilutions. The diluted sample was inoculated on nutrient agar plates by spread plate technique. The plates were incubated for $24-48 \mathrm{hrs}$ and the growth of microorganisms was noted. The microbial population was calculated. Population of microorganisms present in 1 $\mathrm{gm}$ of soil sample $=$ Average no. of colonies X plate detection factor. The cultures were morphologically and biochemically identified by staining like simple staining and gram staining. Biochemical tests like IMVIC, TSI, catalase, oxidase, nitrate reduction, litmus milk reaction, carbohydrate fermentation test, starch hydrolysis, gelatin hydrolysis, etc. The isolated bacterial strains were inoculated on enriched Bushnell Hass agar with $4 \%$ concentration of diesel for 7 days. The OD value read at $550 \mathrm{~nm}$. The DNA of the sample was isolated using cTAB method. The 16S rRNA of isolate was amplified using the universal primers 8F (5'AGAGTTTGATCCTGGCTCAG) and 1541R(50- AAGGAGGTGATCCAGCCGCA-3'). The amplicon was run on the agarose gel and they were eluted and sequenced. The sequence similarity was analysed by using BLAST. The sequence was submitted in the NCBI Gen Bank. 


\section{Results}

The result of the bacterial count showed $38.67 \pm 6.03 \times 10^{5} \mathrm{CFU} / \mathrm{ml}$. Among the 15 distinct colonies 5 colonies showed gram positive cocci (N1, N7, N8, N11 and N12,) and 7 gram positive rod (N2, N3, N5, N6, N9, $\mathrm{N} 13$ and N14) and 3 gram negative rod (N4, N10 and N15) (Table 1). Biochemical characters of the isolated bacterial strains showed that N1 Staphylococcus sp., N7, N8, N11 and N12, Micrococcus sp., N2, N3, N5, N6, N9, N13 and N14 Bacillus sp., N4 Escherchia sp., N10 and N15 Pseudomonas sp. Bacillus sp. Pseudomonas $s p$. and Micrococcus sp. was able to grow well up to $4 \%$ of diesel. The effectively growing microorganisms isolated from diesel polluted soil were 16S rRNA sequenced. From the fifteen isolates N5, N10 and N12 isolates showed the higher absorbance inferring their degradation potential. The organism was biochemically characterized, 16S rRNA sequenced and identified N5 as Bacillus sp. N10 as Pseudomonas putita gram negative bacteria with 1535bp and N12 identified as Micrococcus luteus with 992bp.

\section{Discussion}

Petroleum diesel on an average share $21 \%$ of all spill incidents. It is estimated that 3.3 million barrels of petroleum diesel are consumed daily for transportation, residential, commercial, and industrial uses (Lidderdale, 1993). Ever increasing population increases misuse of environment lead to production of variety of contaminant and toxic compounds. Safe removal of such pollutants as becomes the challenge of the day, increasing the demand on techniques and technology for the same. Bioremediation has been identified as safe technique in which using microbes as biological agent is effective. Sufficient indigenous microbial population with effective degradation capacities and the environmental conditions are crucial in the in situ bioremediation process (Bento et al., 2005; Seklemova et al., 2001).

Bacteria form the most abundant and predominant organisms among the different microorganisms inhabiting the soil. Bacteria are primitive, prokaryotic microscopic unicellular microorganisms that grow on nutrient media. Dilution plate count technique is the common analytical method used for identification, isolation and enumeration of viable/living of soil bacteria. These organisms range from 1,00000 to several hundred millions per gram of soil depending upon the biophysical and biochemical conditions of the soil. In the present context hydrocarbon pollution has become a global concern (Wang et al., 1994), due to their long long persistence in the environments and attributed to low numbers of hydrocarbon-utilizers leading to toxic effect on natural flora (Amund and Igiri, 1990; Atlas, 1991; Vidal, 2001; Hamamura, et al., 2006). Therefore the present study was able to isolate $38.67 \pm 6.03 \times 10^{5} \mathrm{CFU}$ micro organisms in one gram of diesel contaminated soil.

Generally the soil bacteria can be classified into three groups Cocci (round/spherical), Rod-shaped and bacilli I spirllum (cells with long wavy chains). Among the three classified bacterial groups Bacilli shaped bacterial are numerous followed by cocci shaped and bacteria with spirilla in soil. The present study was able to identify seven cocci and thirteen rod which shows the hydrocarbon polluted nature of the soil.

The biochemical characterization of the bacterial isolates obtained from the diesel polluted soil revealed that 12 of them were gram positive and 3 gram negative. Among the 12 gram positive organism one of them were cocci showed positive to methyl red, catalase and mannitol test identified as Staphylococcus aureus as per Cappuccino manual, seven of them were methyl red negative, spore forming, starch caesin positive and VP positive identified as Bacillus anthracis four of them were positive for catalase and urease and positive for mannitol identified as Micrococcus. Among the gram negative organisms one rod species were positive to urease lactose and methyl red, indole and positive for EMB agar and identified as E. coli. Two of them were positive to starch and negative to indole, methyl red, VP and identified Pseudomonas. All the above five species were reported by several authors at different studies.

Microorganisms generally require carbon sources for their growth (Andrew and Jackson, 1996; Giordani et al., 1998; Lehtola et al., 1998; Vidali, 2001). Pseudomonas stutzeri has the higher degrading diesel capacity with Catechol 23 dehydroginase which is one of the hydrocarbon degrading gene (Karthika et al., 2014a). Bacillus subtilis and Pseudomonas fluorescens also has high degradation capacity (Karthika et al., 2014b). Bacillus thuringiensis was identified has high potential degradation of kerosene isolated from the contaminated soil (Archaya et al., 2014)

The present study was able to isolate fifteen different isolates from the diesel contaminated soil and three of them are effective degrader. They were morphologically and biochemically analyzed and identified as Bacillus sp., Pseudomonas pudita and Micrococcus luteus by 16s r RNA sequencing. The present study was able to show that these bacteria steadily grow in $4 \%$ diesel concentration where increasing value of absorbance showed growth of the organism. Such information is useful in evolving effective strategies for bioremediation of hydrocarbon in the soil.

\section{Acknowledgement}

We thank our Chairman Dr. M. Karunanithi for providing infrastructure facilities. 


\section{Bibiliography}

[1] Amund O.O. and Adebiyi A.G. 1991. Effect of viscosity on the biodegradability of automotive lubricating oils. Tribology International. 24: 235-237.

[2] Andrew, R.W.J. and J.M. Jackson, 1996 Pollution and waste management. In Environmental Science: The Natural Environment and Human Impact, Longman, Singapore Publishers Ltd., pp: 281-297

[3] Archaya, S., Gopinath, L.R., Sangeetha, S. and Bhuvaneshwari, R., 2014. Molecular characterization of kerosene degrading bacteria isolated from kerosene polluted soil. Int J Adv Res, 2(4), pp.1117-1124.

[4] Atlas, R. M.1992. Petroleum microbiology. In: Lederberg J (ed) Encyclopedia of microbiology. Academic press, Baltimore pp. 363369.

[5] Bento, F.M., Camargo, F.A.O., Okeke, B. C., Frankenberger, I.F. 2005. Comparative bioremediation of soils contaminated with diesel oil by natural attenuation, biostimulation and bioaugmentation. Bioresource Technology. 96.1049 - 1055.

[6] Giordani, G., Donnelly, A. and Azzoni, R. 1998. The uptake of inorganic phosphate by Z. noltii in the Basin d' Arcachon. In: Proceedings (Handbook) of Summer Conference of the Society for Applied Microbiology, University of Lancaster, UK, pp. 22-23

[7] Hamamura,N., Fukui, M., Ward, D.M.and Inskeep, W.P. 2008. Assessing soil microbial populations responding to crude-oil amendment at different temperatures using phylogenetic, functional gene (alkB) and physiological analyses. Environmental Science and Technology. 42. 7580-7586.

[8] Karthika, R., Gopinath, L.R., Archaya, S. and Bhuvaneswari, R., 2014b. Isolation and identification of microrganism from diesel and petrol contaminated soil. International Journal of Applied research, 2(10), pp.676-682.

[9] Karthika, R., Gopinath, L.R., Archaya, S. and Bhuvaneswari, R., 2014a. Isolation of diesel degrading bacteria, identification of Catechol gene and its biogas production. IOSR Journal of Environmental Science, Toxicology and Food Technology (IOSRJESTFT), 8 (10) 76-82.

[10] Lehtola, M., Miettinen, I. and Vartianen, T. 1998. Purification of drinking water phosphorus and bacterial growth. In: Proceedings (Handbook) of summer conference of the society for applied microbiology, University of Lancaster, UK), pp 16-17

[11] Lidderdale, T.1993. Demand, supply, and price outlook for low-sulfur diesel fuel. In Energy Information Adminismtion. Short term energy outlook annual supplement DOE-E\&0202 (93).

[12] Massol-Deya, A. A., Rodriguez-Martinez, E. M., Perez Ex Schadt, C. W., and Zhou, J. 2006. Microbial diversity and bioremediation of a hydrocarbon contaminated aquifer (Vega Baja, Pueto Rico), Int J Environ Res Publ Health 3(3), 292.

[13] Okerentugba, P.O and Ezeronye, O.U. 2003. Petroleum degrading potentials of single and mixed microbial cultures isolated from rivers and refinery effluent in Nigeria. African Journal of Biotechnol. 2. $288-292$

[14] Seklemova E, Pavlova A, Kovacheva K (2001) Biostimulation based bioremediation of diesel fuel: field demonstration. Biodegradation 12:311-316.

[15] Thomassin - Lacroix, E.J.M., Eriksson, M., Reimer, K.J., and Mohn, W.W. 2002 Biostimulation and bioaugmentation for onsite treatment of weathered diesel fuel in Arctic soil. Appl. Microbiol. Biotectnol. 59. 551 - 556.

[16] Vidali, M, 2001. Bioremediation. An overview. Pure Appl. Chem. 3: $1163-1172$

[17] Vinas, M., Griffol, M., Sabate,J. and Solana,. A.M. 2002. Biodegradation of a crude oil by three microbial consortia of different origins and metabolic capabilities. Journal of Indian Microbiology. Biotechnol. 28,252-260.

[18] Watanabe, K., Kodama, Y., Syutsubo, K. and Harayama, S. 2000. Molecular characterization of bacterial populations in petroleumcontaminated groundwater discharged from underground crude-oil-storage cavities. Applied and Environmental Microbiology. 66, 4803-4809.

Table 1. Morphological and Biochemical characters of bacterial strains isolated from diesel polluted soil.

\begin{tabular}{|c|c|c|c|c|c|c|c|c|}
\hline \multirow[b]{2}{*}{$\begin{array}{l}\dot{\mathbf{Z}} \\
\dot{\boldsymbol{n}}\end{array}$} & \multirow[b]{2}{*}{ 总 } & \multirow[b]{2}{*}{ 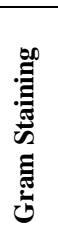 } & \multirow[b]{2}{*}{ ڤั) } & \multirow[b]{2}{*}{ Shape } & \multicolumn{3}{|c|}{ Colony Characterization } & \multirow[b]{2}{*}{ 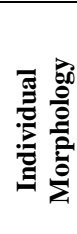 } \\
\hline & & & & & Surface & Color & Transparency & \\
\hline 1 & N1 & + & - & Round & Smooth & Golden Yellow & Translucent & Cocci \\
\hline 2 & N2 & + & + & Radiciform & Rough & Milk-white & Translucent & Rod \\
\hline 3 & N3 & + & + & Radiciform & Rough & Milk-white & Translucent & Rod \\
\hline 4 & N4 & - & - & Circular & Smooth & Pink & Opaque & Rod \\
\hline 5 & N5 & + & + & Radiciform & Rough & Milk-white & Translucent & Rod \\
\hline 6 & N6 & + & + & Radiciform & Rough & Milk-white & Translucent & Rod \\
\hline 7 & N7 & + & - & Round & Smooth & Yellow & Translucent & Cocci \\
\hline 8 & N8 & + & - & Round & Smooth & Yellow & Translucent & Cocci \\
\hline 9 & N9 & + & + & Radiciform & Rough & Milk-white & Translucent & Rod \\
\hline 10 & N10 & - & - & Round & Rough & Bluish green & Opaque & Rod \\
\hline 11 & N11 & + & - & Round & Smooth & Yellow & Translucent & Cocci \\
\hline 12 & N12 & + & - & Round & Smooth & Yellow & Translucent & Cocci \\
\hline 13 & N13 & + & + & Radiciform & Rough & Milk-white & Translucent & Rod \\
\hline 14 & N14 & + & + & Radiciform & Rough & Milk-white & Translucent & Rod \\
\hline 15 & N15 & - & - & Round & Rough & Bluish green & Opaque & Rod \\
\hline
\end{tabular}


Table 2. Biochemical characterizes of bacterial strains isolated from diesel soil and identified genera

\begin{tabular}{|c|c|c|c|c|c|c|c|c|c|c|c|c|}
\hline Samples & Ind. & MR & Vp & Cat. & Cit. & Ure. & Oxide & Starch & Lact. & Alk. & $\mathrm{H}_{2}$ S & Genera \\
\hline N1 & - & + & - & + & - & - & - & - & - & + & A & Staphylococcus sp. \\
\hline N2 & - & - & + & + & + & - & + & + & + & + & + & Bacillus sp. \\
\hline N3 & - & - & + & + & + & - & + & + & + & + & + & Bacillus sp. \\
\hline N4 & + & + & - & - & - & - & - & - & + & - & - & E. Coli \\
\hline N5 & - & - & + & + & + & - & + & + & + & + & + & Bacillus sp. \\
\hline N6 & - & - & + & + & + & - & + & + & + & + & + & Bacillus sp. \\
\hline N7 & - & - & - & + & - & + & - & - & - & - & - & Micrococcus sp. \\
\hline N8 & - & - & - & + & - & + & - & - & - & - & - & Micrococcus sp. \\
\hline N9 & - & - & + & + & + & - & + & + & + & + & + & Bacillus sp. \\
\hline N10 & + & - & - & + & + & + & + & - & - & NA & - & Pseudomonas sp. \\
\hline N11 & - & - & - & + & - & + & - & - & - & - & - & Micrococcus sp. \\
\hline N12 & - & - & - & + & - & + & - & - & - & - & - & Micrococcus sp. \\
\hline N13 & - & - & + & + & + & - & + & + & + & + & + & Bacillus sp. \\
\hline N14 & - & - & + & + & + & - & + & + & + & + & + & Bacillus sp. \\
\hline N15 & + & - & - & + & + & + & + & - & - & NA & - & Pseudomonas sp. \\
\hline
\end{tabular}

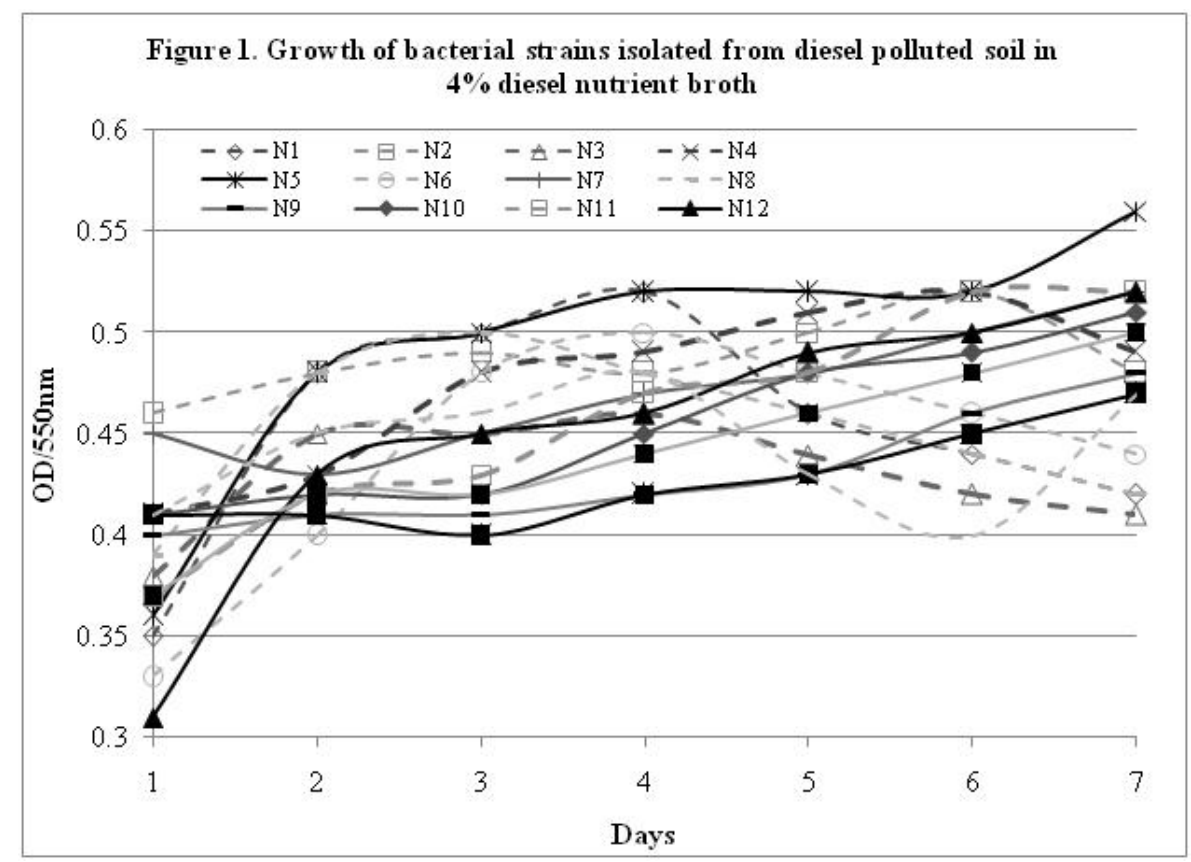

IOSR Journal of Biotechnology and Biochemistry (IOSR-JBB) is UGC approved Journal with Sl. No. 4033, Journal no. 44202.

Karthika . R. "Isolation and Identification of Effective Hydrocarbon Degrading Bacteria from Diesel Polluted Soil." IOSR Journal of Biotechnology and Biochemistry (IOSR-JBB) 3.3 (2017): 60-63. 